\title{
Etapas necessárias à elaboração e implantação de produtos para disseminação de informações sobre Mercado de Trabalho no âmbito de um Observatório de Políticas Públicas
}

\author{
Necessary steps for the elaboration and implantation of \\ products for the dissemination of information about the \\ Labor Market within the scope of a Public Policy \\ Observatory
}

\section{Eliane Navarro Rosandiski ${ }^{1}$}

\begin{abstract}
RESUMO
A funcionalidade termo observatório quando utilizado nas ciências sociais está vinculada ao compartilhamento de informações que contribuam para o aperfeiçoamento das políticas púbicas e promovam o desenvolvimento, tendo como parâmetro os interesses coletivos. Este artigo relatará a trajetória do Projeto de Extensão Universitária que teve como objetivo sistematizar as atividades de coleta, organização, análise e divulgação no Observatório PUCCampinas das informações relativas ao Mercado de Trabalho na Região Metropolitana de Campinas (RMC). O público-alvo das ações propostas neste projeto são os cidadãos, os formuladores de políticas públicas, a mídia e toda a comunidade interna da universidade. Metodologicamente, o projeto de extensão seguiu os seguintes passos: a organização das bases de dados; a construção de indicadores; e por fim, a produção e compartilhamento de estudos capazes de dar visibilidade à realidade econômica vivida pela RMC. Através da intermediação do Observatório da PUC-Campinas esperava-se que: (1) a sociedade pudesse compreender melhor seus problemas e as ações públicas; (2) a formulação das políticas públicas pudessem, cada vez mais, ser circunscritas às demandas estabelecidas pela sociedade; e (3) a PUC-Campinas assumisse um papel protagonista no debate das questões relacionadas ao desenvolvimento da RMC.
\end{abstract}

Palavras-chave: Mercado de Trabalho. Políticas Públicas. Desenvolvimento Regional

\section{ABSTRACT}

The functionality of the term observatory when used in the social sciences is linked to the sharing of information that contributes to the improvement of public policies and promotes development, based on collective interests. This paper will report on the trajectory of the University Extension Project at the PUC-Campinas Observatory, whose objective was to systematize, collect, organize, analyse and disseminate information about the Labor Market in the Metropolitan Region of Campinas (MRC). The target audience for the actions proposed in the project are citizens, policymakers, the media and the entire internal community of the university. Methodologically, the extension project executed the following steps: the organization of the databases; the construction of indicators; and finally, the production and sharing of studies, in order to give visibility of the economic reality lived by the MRC. Through the Observatory of PUC-Campinas it was hoped that: (1) society could better understand its problems and public actions; (2) the formulation of public policies could be more and more circumscribed to the demands established by society; and (3) PUC-Campinas would play a leading role in discussing issues related to the development of the MRC.

Keywords: Label market. Public policy. Regional development.

\footnotetext{
${ }^{1}$ Doutora em Economia Social e do Trabalho (IE/Unicamp) e Professora-extensionista da PUC-Campinas. Campinas, São Paulo, Brasil. eliane.rosandiski@gmail.com. Orcid: https://orcid.org/0000-0001-6969$\underline{2234}$
} 


\section{INTRODUÇÃO}

O termo Observatório vem sendo utilizado com frequência nos mais diversos âmbitos do conhecimento, no campo social se destaca por sua funcionalidade e importância para a esfera pública e para os demais atores da sociedade, visto que atua como meio de divulgação de informação e pesquisadores sociais.

Desse modo, quando atrelado à discussões da esfera social, sua definição vai além da original, pois, ao facilitar o acesso à informação de qualidade, contribui para a tomada de decisões entre diversas categorias de poder.

Em função do processo de globalização e, em consequência, a intensa necessidade de se produzir e consumir informações há o reconhecimento de que os observatórios se constituem em importantes instrumentos de democracia e de defesa de interesses de uma maioria, inúmeros atores e instituições sociais vêm criando observatórios de diversos tipos visando acompanhar de forma sistemática um setor ou temas específicos e promover a difusão de informações, conforme apontam Albornoz e Herschmann (2006).

Reconhecendo a importância da atuação de um Observatório junto à comunidade, o presente artigo tem como objetivo relatar a experiência da Pró-Reitoria de Extensão e Assuntos Comunitários (PROEXT) da PUC-Campinas para implementação de uma plataforma para disseminar informações e indicadores socioeconômicos sobre a Região Metropolitana de Campinas (RMC). A implantação do Observatório PUC-Campinas teve início de 2018 e envolveu um conjunto de quatro professores extensionistas, cada qual atuando nos seguintes eixos temáticos: (a) Sustentabilidade e Desafios do Milênio; (b) Indicadores Sociais; (c) Produção e Comércio Internacional; (d) Trabalho, Renda e Emprego.

Mais especificamente, este artigo tem como foco os desafios enfrentados na execução do Projeto: Observatório Econômico PUC-Campinas, concentrado na área de Trabalho, Renda e Emprego. Tal projeto tem como objetivo geral a coleta, sistematização, a análise e divulgação de informações relativas ao mercado de trabalho na Região Metropolitana de Campinas (RMC)

Este projeto de extensão universitária se inicia com um importante parceiro local: a Agência Metropolitana de Campinas (AGEMPCAMP), importante instituição para proposição de temas, formulação, articulação e debate de políticas públicas.

Para relatar tal experiência, o presente artigo divide-se, para além desta introdução, em quatro partes. Na primeira será feita uma breve contextualização e definição do conceito de 
Observatório, que visa destacar a importância do Observatório PUC- para o meio em que está inserido. Após isso, será feita uma apresentação da metodologia adotada para a construção dos primeiros informativos mensais e Estudos Temáticos propostos pelo projeto extensão. A terceira parte deste artigo se destina à apresentação e discussão dos resultados obtidos neste primeiro ano de projeto e a repercussão destes na RMC. Por fim, têm-se as considerações finais acerca de todo o processo, fazendo um comentário geral de toda a experiência vivenciada.

\section{MATERIAIS E MÉTODOS}

Antes de inserir a discussão acerca do Observatório da PUC-Campinas, é necessário compreender o que são Observatórios e qual sua importância para a sociedade e o meio em que estão inseridos.

Na literatura, é possível encontrar uma diversidade de conceitos e concepções acerca dos Observatórios, podendo estes variarem conforme sua finalidade, temática e/ou atuação. Essa amplitude de definição dificulta sua identificação e análise, além de existir uma reflexão pouco abundante acerca desses novos organismos. (ALBORNOZ, HERSCHMANN, 2006; ORTEGA, DEL VALLE, 2010 apud SOARES et al., 2018)

Observatório pode ser considerado como um espaço, munido de recursos humanos ou tecnológicos, destinado à observar, acompanhar e analisar determinados temas, divulgando informações e atendendo a algum objetivo. Tais observatórios constituem-se como espaços de informação, promovendo intercâmbio de conhecimentos com trabalhos em rede, reflexão e colaboração.

Beuttenmuller (2007) realiza um importante resgate histórico e conceitual acerca dos da importância e funcionalidade dos observatórios na disseminação de informações. O autor mostra que, já na década de 90, os primeiros observatórios resultam da parceria entre universidades, ONG e movimentos sociais para a produção de informações.

Beuttenmuller (2007) pontua que nestes últimos 20 anos, “o objetivo principal dos observatórios tem sido produzir e disponibilizar informações e análises sobre as políticas locais aos atores sociais e cidadãos" (p. 13) e que podem ser separados em dois grupos observatórios da sociedade civil e observatórios governamentais. De um lado, nos 
observatórios da sociedade civil, a disseminação de informações sobre o funcionamento do aparelho do Estado estaria endereçada aos atores sociais, para fundamentar suas ações de controle social e de participação destes atores nas esferas públicas. Por outro lado, o caso dos observatórios governamentais se diferencia do anterior, pois seu principal objetivo é dar maior transparência às políticas públicas e por isto, as informações sobre as políticas assumem caráter de prestação de contas à sociedade.

Albornoz e Herschmann (2006), na tentativa de avançar na conceituação, mostram que os observatórios são divididos em dois conjuntos, com dois enfoques: observatório fiscal - em que funcionam como articuladores de cidadania, onde se pode monitorar os meios de comunicação - e os observatórios think tank (repositório de reflexões) - onde são considerados como novos meios que colaboram para formulação de políticas públicas através de suas intervenções e reflexões.

Dentro dessa percepção, os observatórios fiscais estariam diretamente ligados à cidadania e a democracia participativa, uma vez que atuariam como uma espécie de ouvidoria dos meios de comunicação visando e orientando-se para denunciar o grande poder de grupos midiáticos. Em paralelo, os think tank possuem uma função muito mais voltada para a orientação visando a elaboração de ideias e/ou aperfeiçoamento de políticas públicas capazes de gerar um desenvolvimento industrial/cultural, respeitando os interesses e opiniões de uma maioria, do que uma função de criticar ou denunciar.

De um modo geral, pode-se dizer que há um consenso de que uma das contribuições dos observatórios é integrar redes de participantes e meios/nichos específicos para disseminar conteúdos de determinados focos, sendo eles informações, metodologias, indicadores, resultados sobre determinado tema. Tal rede pode proporcionar ganhos importantes para o desenvolvimento não só de processos e estudos, como também modificar o meio em que o grupo social está inserido.

Acerca disso, Serafim (2008) revela outro importante fator acerca da funcionalidade dos observatórios ao elencar que para haver um controle social é preciso que todos os cidadãos tenham acesso à informação, participem de canais de debates e interfiram sobre a construção/modificação das políticas públicas. A autora pontua ainda que a falta de meios que promovam o acesso à informação é um dos principais desafios encontrados hoje por diversos 
atores da sociedade, sobretudo movimentos sociais e pesquisadores acadêmicos que visem a ampliação deste controle social.

Fica claro, portanto, que por meio de observatórios é possível ampliar a participação dos cidadãos nas discussões políticas, contribui para a construção de uma gestão mais participativa e, através disso, dar sequência ao controle social das políticas públicas. Diante disso, caberia aos Observatórios compartilhar com a sociedade informações diversas, sejam elas qualitativas ou quantitativas, e criar canais de comunicação capazes de promover essa aproximação entre sociedade e esfera pública/política.

Um último aspecto considerado diz respeito à pertinência e a mobilização dos atores sociais em torno do tema apresentado à sociedade/comunidade. Vargas (2015) ao relatar sua experiência de implantação do Observatório Social do Trabalho ${ }^{2}$ para monitorar as transformações do mercado de trabalho, o autor chama atenção a necessidade de estreitar os laços e parcerias com os atores e instituições ligadas ao mundo do trabalho, para qualificar a intervenção no âmbito das políticas públicas de emprego.

Compreendida sua importância para a dinâmica política e social, é necessário agora discutir a proposta de lançamento do Observatório da PUC-Campinas e sua importância para a Região Metropolitana de Campinas (RMC).

A estruturação do Observatório PUC-Campinas é uma ação conjunta da Pró-Reitoria de Extensão e Assuntos Comunitários da PUC-Campinas (PROEXT), que envolve um grupo de professores extensionistas e discentes da Universidade. Tal ação visa compreender e analisar indicadores, temas e tendências que possam contribuir não só para a realidade regional em que está inserido, como também para um olhar mais amplo sobre a realidade nacional.

Diferentes públicos tendem a ser beneficiados, tanto internos à Universidade quanto externos, que podem ser agrupados da seguinte maneira:

\footnotetext{
${ }^{2} \mathrm{O}$ objetivo do artigo foi analisar a experiência do Observatório Social do Trabalho, projeto de extensão da Universidade Federal de Pelotas (UFPel).
} 
a) público interno - sendo tanto discentes quanto docentes, que passarão a contar com um campo de indicadores abrangente, facilitando o embasamento de estudos e discussões;

b) público externo em geral - como os cidadãos da região, que contarão com um amplo espaço de divulgação de informações, com fácil acesso e de fácil compreensão. As prefeituras e subprefeituras, sobretudo pela característica de socialização de dados, construção de indicadores e análises, que poderão subsidiar a tomada de decisões na formatação de políticas públicas. E as mídias locais, que não só se aproximam da comunidade universitária, como também passa a contar com importante e confiável fonte de informações, dados e opiniões frequentemente utilizados na elaboração de matérias e conteúdos; e

c) as entidades parceiras - diretamente interessadas e envolvidas na construção de indicadores e de temáticas abordadas pelo observatório.

A RMC como objeto de análise foi escolhida por sua importância para a economia paulista. Ela é composta por 20 municípios que apresentam complementaridades econômicas importantes: Americana, Artur Nogueira, Campinas, Cosmópolis, Engenheiro Coelho, Holambra, Hortolândia, Indaiatuba, Itatiba, Jaguariúna, Monte Mor, Morungaba, Nova Odessa, Paulínia, Pedreira, Santa Bárbara d'Oeste, Santo Antônio de Posse, Sumaré, Valinhos e Vinhedo.

Em seu perímetro são desenvolvidas atividades de alta e média intensidade tecnológica e serviços, incluindo comércio, serviços especializados e produção de conhecimento científico pelas Universidades e Institutos de Pesquisas da Região. No mais, conta também com a importante participação do Aeroporto Internacional de Viracopos que dá à Região importante papel na dinâmica do transporte internacional de cargas do país.

Dentro do Estado, em função desse dinamismo econômico, a RMC é a segunda Região Metropolitana mais importante, sobretudo no que tange a participação relativa no Produto Interno Bruto e também nas operações de comércio exterior. Esse dinamismo se reflete também na geração de emprego e renda no estado de São Paulo. No mais, vale destacar que a RMC é a segunda Região Metropolitana com maior densidade demográfica do Estado, sendo predominantemente urbana e uma das que apresentaram maior crescimento populacional nos últimos anos. 
Um último ponto a ser considerado na constituição do Observatório PUC-Campinas diz respeito à importância da parceria estabelecida com a Agência Metropolitana de Campinas (AGEMPCAMP), que teve como objetivo compartilhar informações, propor temas e contribuir para o debate de políticas públicas e o desenvolvimento metropolitano.

\section{METODOLOGIA DE COLETA, SISTEMATIZAÇÃO E DIVULDAÇÃO DE INFORMAÇÕES}

Como discutido anteriormente, o projeto Observatório Econômico da PUC-Campinas tem como objetivo geral coletar, sistematizar, analisar e disponibilizar, de maneira fácil e acessível, para a sociedade as informações sobre o mercado de trabalho da RMC. A escolha dessa temática deve-se ao reconhecimento da importância da compreensão do impacto da dinâmica econômica sobre o mundo do trabalho. Mais especificamente, deve-se ter como referência o impacto de transformações tecnológicas, organizacionais, ambiente políticoinstitucional sobre a forma de uso do trabalho.

Deste objetivo geral, desdobraram-se os seguintes objetivos específicos:

a) Adequação do sítio da PUC-Campinas para hospedar o Observatório Econômico da PUC-Campinas;

b) Construção do Banco de Dados;

c) Construção de Indicadores;

d) Produção de Informativos Mensais;

e) Produção de Estudos Temáticos.

A prospecção de informações relacionadas ao tema de Trabalho e Renda para construção de indicadores pode ser realizada através da consulta de dados disponibilizados pelo Instituto Brasileiro de Geografia e Estatística (IBGE) e as informações administrativas disponibilizadas pelo Ministério do Trabalho e Emprego (MTE), por meio da Relação Anual de Informações Sociais (RAIS) e do Cadastro Geral de Emprego e Desemprego (CAGED).

As bases de dados estatísticas do RAIS e CAGED, são as que mais se adequam ao objetivo de sistematizar e organizar as informações, pois são as únicas que permitirem, por município, realizar uma análise do mercado de trabalho por nível de instrução, setor, idade, grande setor, subsetor, sexo, grupos de ocupação, horas trabalhadas, tipos de contratos de trabalho, salário, dentre outros aspectos do aspecto formal do emprego. Os dados do IBGE 
ajudam a mapear as tendências mais gerais do mercado de trabalho, mas infelizmente não estão disponíveis por município.

Para além deste ponto, foi utilizado também como procedimento metodológico a construção de indicadores capazes de permitir um melhor acompanhamento da realidade de emprego e renda na RMC. A construção destes indicadores tomou como base em conceitos teóricos já consolidados, como por exemplo, salário médio, participação de mulheres no mercado de trabalho, relação entre níveis de remuneração.

De modo externo à universidade, a participação nas Câmaras Temáticas, resultante da parceria com AGEMCAMP, trouxe como desafio a elaboração estudos que visavam incentivar, aprofundar e subsidiar o diálogo realizado entre os representantes dos municípios da RMC. Vale dizer as Câmara Temáticas, organizadas pela AGEMCAMP objetivam mobilizar os representantes municipais e realizar discussões acerca das demandas e das políticas públicas integradas para a RMC.

Por fim, para divulgar e democratizar o acesso à informação optou-se pela produção de dois formatos de publicação disponibilizados no site do Observatório PUC-Campinas: (i) Informativos Mensais, que são publicações em linguajar simples e breves, tratando sobre os principais resultados do mercado de trabalho na RMC. (ii) Estudos Temáticos, publicações mais estruturadas sobre tema específico, decidido tanto internamente com a equipe do Observatório da PUC-Campinas, como a partir dos diálogos travados com a instituição parceira, neste caso a AGEMCAMP.

Ainda que o segundo tipo de publicação assuma um formato mais acadêmico, há uma preocupação em tratar os conceitos e os resultados de forma simples e acessível. Este cuidado garante que tais publicações sejam capazes de atuar como importante meio de monitoramento da dinâmica do emprego e da renda e que o observatório cumpra sua função de estabelecer um diálogo com a sociedade.

Reiterando, com a implantação do Observatório PUC-Campinas, esperava-se que (i) a sociedade pudesse compreender melhor seus problemas e as ações públicas adotadas para resolvê-los; (ii) a divulgação destas informações subsidiassem a formulação de políticas públicas mais adaptadas às demandas sociais; e (iii) a universidade assumisse um papel de protagonista no debate das questões relacionadas à RMC. 


\section{RESULTADOS E DISCUSSÃO}

Como visto no item anterior, a primeira etapa era vital para que as informações pudessem ser divulgadas, porém sua execução dependia de outros departamentos da Universidade. O esforço de coordenação da ProExt viabilizou a inserção da plataforma no site da Universidade e o Observatório pode oficialmente ser disponibilizado para a comunidade interna e externa em 12 junho de 2018.

Figura 1 - Plataforma do Observatório PUC-Campinas

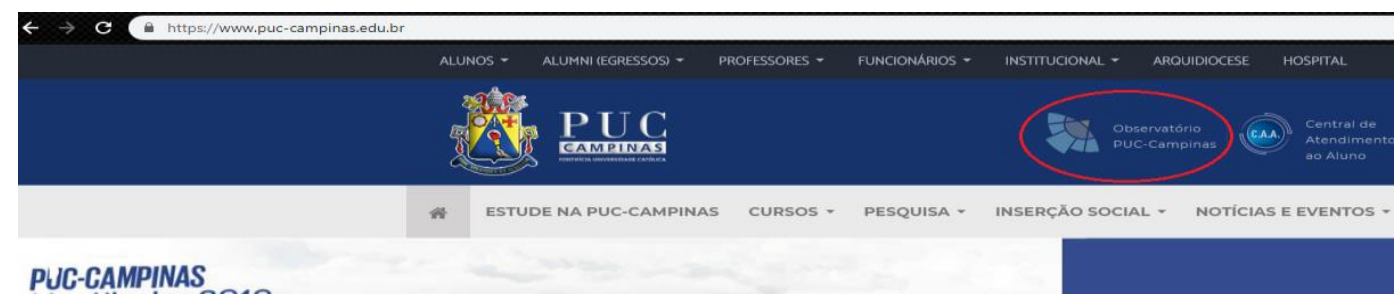

O outro ponto crucial diz respeito à construção de uma base de dados com um acervo de informações referentes ao Emprego e Renda para o Brasil, São Paulo e RMC, com diversos níveis de detalhamento. Tal base foi arquitetada a fim de contribuir com futuras análises para alimentação do Observatório.

O primeiro informativo oficialmente produzido e divulgado foi no mês de Agosto, acerca dos resultados de Julho. A elaboração dos Informativos permite ter uma maior compreensão sobre a dinâmica do mercado de trabalho no mês e no acumulado do ano, referenciados ao mesmo período no ano anterior. Além disso, há um referenciamento da RMC em relação ao Estado de São Paulo e Brasil.

Os Informativos possuem uma periodicidade mensal e, para facilitar o acompanhamento dos indicadores, possui sempre a mesma estrutura: (I) tópicos com os pontos de destaques do saldo de emprego na RMC; (II) Principais Indicadores referentes à temática; (III) Perfil do Emprego na RMC, por município, escolaridade, faixa de idade e por setor de atividade. Os mesmos foram produzidos e divulgados com a seguinte identidade visual:

Figura 2: Identidade Visual dos Informativos 


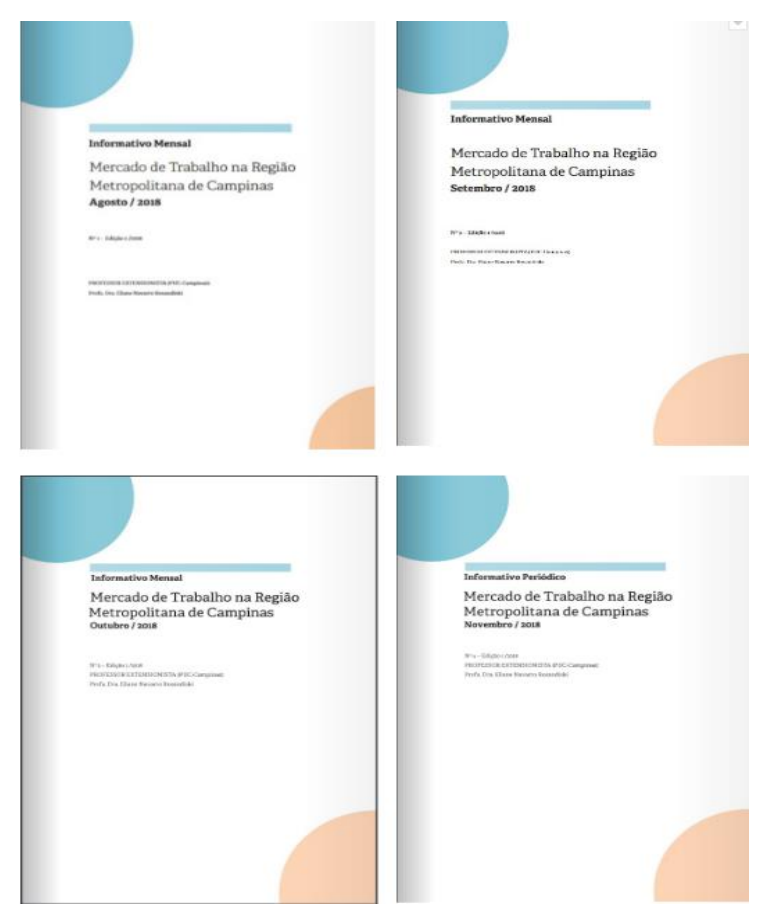

Fonte: Observatório PUC-Campinas

As informações e indicadores são apresentados na forma de quadros, gráficos tabelas. Seguem abaixo alguns exemplos:

Gráfico 1. Evolução do Saldo do Emprego na RMC, entre Janeiro e Dezembro de 2018

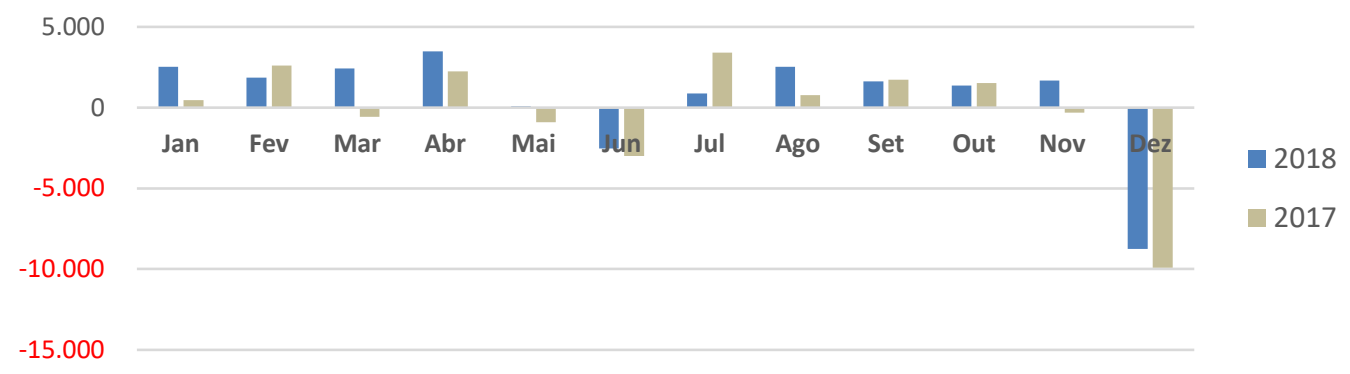

Fonte: Caged,2018.

Gráfico 2. Evolução dos salários médios dos Admitidos na RMC - de janeiro a Dezembro de 2018 


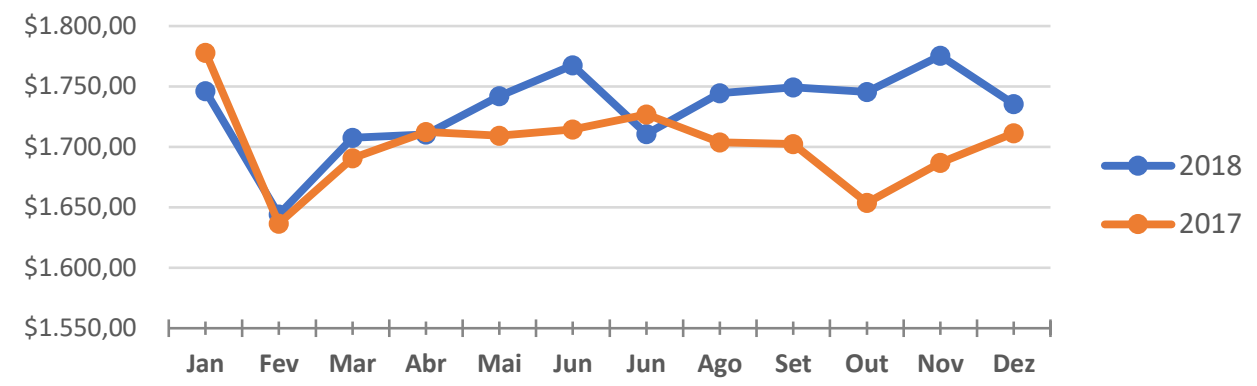

Fonte: Caged,2018.

Tabela 1. Características do Saldo de Emprego gerado na RMC, por município

\begin{tabular}{lrrr|rrr}
\hline & \multicolumn{3}{c|}{ Saldo do Emprego } & \multicolumn{3}{c}{ Salários Médios dos Admitidos } \\
\cline { 2 - 7 } & Dec-18 & Nov-18 & Dec-17 & Dec-18 & Nov-18 & Dec-17 \\
\hline Sp-Americana & -818 & -24 & -1.234 & $\mathrm{R} \$ 1.597,26$ & $\mathrm{R} \$ 1.745,48$ & $\mathrm{R} \$ 1.665,87$ \\
Sp-Artur Nogueira & -102 & 49 & -76 & $\mathrm{R} \$ 1.467,02$ & $\mathrm{R} \$ 1.514,32$ & $\mathrm{R} \$ 1.351,30$ \\
Sp-Campinas & -2.070 & 1.057 & -3.218 & $\mathrm{R} \$ 1.714,96$ & $\mathrm{R} \$ 1.773,39$ & $\mathrm{R} \$ 1.694,94$ \\
Sp-Cosmópolis & -154 & -92 & -180 & $\mathrm{R} \$ 1.630,84$ & $\mathrm{R} \$ 1.673,70$ & $\mathrm{R} \$ 1.559,32$ \\
Sp-Engenheiro Coelho & -132 & -90 & -242 & $\mathrm{R} \$ 1.669,45$ & $\mathrm{R} \$ 1.663,09$ & $\mathrm{R} \$ 1.832,02$ \\
Sp-Holambra & -107 & 16 & 13 & $\mathrm{R} \$ 1.433,67$ & $\mathrm{R} \$ 1.540,25$ & $\mathrm{R} \$ 1.380,93$ \\
Sp-Hortolândia & -333 & 101 & -421 & $\mathrm{R} \$ 2.056,92$ & $\mathrm{R} \$ 1.978,41$ & $\mathrm{R} \$ 1.890,80$ \\
Sp-Indaiatuba & -652 & 168 & -783 & $\mathrm{R} \$ 1.656,42$ & $\mathrm{R} \$ 1.735,36$ & $\mathrm{R} \$ 1.748,92$ \\
Sp-Itatiba & -427 & 15 & -392 & $\mathrm{R} \$ 1.678,11$ & $\mathrm{R} \$ 1.703,64$ & $\mathrm{R} \$ 1.729,47$ \\
Sp-Jaguariúna & -357 & -67 & -165 & $\mathrm{R} \$ 2.172,14$ & $\mathrm{R} \$ 2.117,86$ & $\mathrm{R} \$ 1.868,43$ \\
Sp-Monte Mor & -304 & 21 & -231 & $\mathrm{R} \$ 1.815,06$ & $\mathrm{R} \$ 1.882,35$ & $\mathrm{R} \$ 1.643,88$ \\
Sp-Morungaba & -55 & -13 & -44 & $\mathrm{R} \$ 1.345,79$ & $\mathrm{R} \$ 1.294,73$ & $\mathrm{R} \$ 1.289,46$ \\
Sp-Nova Odessa & -399 & 14 & -236 & $\mathrm{R} \$ 1.663,81$ & $\mathrm{R} \$ 1.617,19$ & $\mathrm{R} \$ 1.731,77$ \\
Sp-Paulínia & 4 & 457 & -633 & $\mathrm{R} \$ 2.264,28$ & $\mathrm{R} \$ 2.181,36$ & $\mathrm{R} \$ 1.810,02$ \\
Sp-Pedreira & -140 & -16 & -160 & $\mathrm{R} \$ 1.501,89$ & $\mathrm{R} \$ 1.409,43$ & $\mathrm{R} \$ 1.498,28$ \\
Sp-Santa Barbara D Oeste & -475 & 87 & -553 & $\mathrm{R} \$ 1.557,52$ & $\mathrm{R} \$ 1.500,71$ & $\mathrm{R} \$ 1.592,51$ \\
Sp-Santo Antônio de Posse & -13 & 35 & -161 & $\mathrm{R} \$ 1.612,70$ & $\mathrm{R} \$ 1.593,08$ & $\mathrm{R} \$ 1.900,79$ \\
Sp-Sumaré & -1.669 & -43 & -570 & $\mathrm{R} \$ 1.607,87$ & $\mathrm{R} \$ 1.713,08$ & $\mathrm{R} \$ 1.771,36$ \\
Sp-Valinhos & -276 & 0 & -363 & $\mathrm{R} \$ 1.671,93$ & $\mathrm{R} \$ 1.879,77$ & $\mathrm{R} \$ 1.730,64$ \\
Sp-Vinhedo & -282 & 7 & -308 & $\mathrm{R} \$ 1.794,00$ & $\mathrm{R} \$ 1.820,77$ & $\mathrm{R} \$ 1.728,71$ \\
Total & -8.761 & $\mathbf{1 . 6 8 2}$ & $\mathbf{- 9 . 9 5 7}$ & $\mathrm{R} \$ \mathbf{1 . 7 3 5 , 5 6}$ & $\mathbf{R} \$ \mathbf{1 . 7 7 5 , 4 4}$ & $\mathbf{R} \$ \mathbf{1 . 7 0 9 , 5 1}$ \\
\hline
\end{tabular}

Fonte: CAGED, 2018

Tabela 2. Característica do Saldo de Emprego por Faixa de Escolaridade na RMC

\begin{tabular}{|c|c|c|c|c|c|c|}
\hline & \multicolumn{3}{|c|}{ Saldo do Emprego } & \multicolumn{3}{|c|}{ Salários Médios dos Admitidos } \\
\hline & Dec-18 & Nov-18 & Dec-17 & Dec-18 & Nov-18 & Dec-17 \\
\hline Analfabeto & -21 & -6 & -57 & $\mathrm{R} \$ 1.385,81$ & $\mathrm{R} \$ 1.424,36$ & $\mathrm{R} \$ 1.327,62$ \\
\hline Até $5^{\mathrm{a}}$ Incompleto & -108 & -40 & -161 & $\mathrm{R} \$ 1.458,40$ & $\mathrm{R} \$ 1.482,01$ & $\mathrm{R} \$ 1.441,44$ \\
\hline $5^{\text {a }}$ Completo Fundamental & -359 & -157 & -350 & $\mathrm{R} \$ 1.431,11$ & $\mathrm{R} \$ 1.470,83$ & $\mathrm{R} \$ 1.400,77$ \\
\hline $6^{\mathrm{a}}$ a $9^{\mathrm{a}}$ Fundamental & -299 & -55 & -522 & $\mathrm{R} \$ 1.506,90$ & $\mathrm{R} \$ 1.483,74$ & $\mathrm{R} \$ 1.388,67$ \\
\hline Fundamental Completo & -903 & -441 & -1.153 & $\mathrm{R} \$ 1.462,71$ & $\mathrm{R} \$ 1.548,66$ & $\mathrm{R} \$ 1.428,60$ \\
\hline
\end{tabular}




\begin{tabular}{lrrr|rrr} 
Médio Incompleto & -605 & 106 & -817 & $\mathrm{R} \$ 1.293,57$ & $\mathrm{R} \$ 1.282,39$ & $\mathrm{R} \$ 1.284,11$ \\
Médio Completo & -3.039 & 2.058 & -3.770 & $\mathrm{R} \$ 1.518,56$ & $\mathrm{R} \$ 1.532,49$ & $\mathrm{R} \$ 1.498,41$ \\
Superior Incompleto & -258 & 139 & -320 & $\mathrm{R} \$ 1.833,20$ & $\mathrm{R} \$ 1.779,48$ & $\mathrm{R} \$ 1.825,55$ \\
Superior Completo & -3.169 & 78 & -2.807 & $\mathrm{R} \$ 3.533,92$ & $\mathrm{R} \$ 3.604,39$ & $\mathrm{R} \$ 3.429,26$ \\
Total da RMC & $\mathbf{- 8 . 7 6 1}$ & $\mathbf{1 . 6 8 2}$ & $\mathbf{- 9 . 9 5 7}$ & $\mathbf{R} \$ \mathbf{1 . 7 3 5 , 5 6}$ & $\mathbf{R} \$ \mathbf{1 . 7 7 5 , 4 4}$ & $\mathbf{R} \mathbf{1 . 7 0 9 , 5 1}$ \\
\hline
\end{tabular}

Fonte: CAGED, 2018

Tabela 3. Característica do Saldo de Emprego por Setor de Atividade na RMC

\begin{tabular}{|c|c|c|c|c|c|c|}
\hline & \multicolumn{3}{|c|}{ Saldo do Emprego } & \multicolumn{3}{|c|}{ Salários Médios dos Admitidos } \\
\hline & Dec-18 & Nov-18 & Dec-17 & Dec-18 & Nov-18 & Dec-17 \\
\hline 1 - Extrativa mineral & -5 & 1 & -6 & $\mathrm{R} \$ 1.879,00$ & $\mathrm{R} \$ 1.787,70$ & $\mathrm{R} \$ 2.334,67$ \\
\hline 2 - Indústria de transformação & -2.430 & -464 & -2.703 & $\mathrm{R} \$ 2.108,25$ & $\mathrm{R} \$ 2.128,97$ & $\mathrm{R} \$ 2.184,71$ \\
\hline 3 - Serviços Ind. de Utilidade Pública & 13 & 51 & 104 & $\mathrm{R} \$ 2.298,49$ & $\mathrm{R} \$ 1.915,72$ & $\mathrm{R} \$ 1.895,76$ \\
\hline 4 - Construção Civil & -51 & 644 & -769 & $\mathrm{R} \$ 2.069,56$ & $\mathrm{R} \$ 1.964,41$ & $\mathrm{R} \$ 1.855,97$ \\
\hline 5 - Comércio & -133 & 1.613 & -174 & $\mathrm{R} \$ 1.523,65$ & $\mathrm{R} \$ 1.551,09$ & $\mathrm{R} \$ 1.524,20$ \\
\hline 6 - Serviços & -4.825 & 42 & -5.214 & $\mathrm{R} \$ 1.684,52$ & $\mathrm{R} \$ 1.745,52$ & $\mathrm{R} \$ 1.637,90$ \\
\hline 7 - Administração Pública & -710 & -5 & -506 & $\mathrm{R} \$ 2.664,79$ & $\mathrm{R} \$ 2.642,95$ & $\mathrm{R} \$ 4.607,65$ \\
\hline 8 - Agropecuária, extr. vegetal, caça e pesca & -620 & -200 & -689 & $\mathrm{R} \$ 1.388,08$ & $\mathrm{R} \$ 1.350,54$ & $\mathrm{R} \$ 1.393,14$ \\
\hline Total da RMC & -8.761 & 1.682 & -9.957 & $\mathbf{R} \$ 1.735,56$ & $\mathbf{R} \$ 1.775,44$ & $\mathbf{R} \$ 1.709,51$ \\
\hline
\end{tabular}

Fonte: CAGED, 2018

Quadro 3: Mulheres no Mercado de Trabalho: Indicadores / DEZEMBRO de 2018

\begin{tabular}{|c|c|c|c|c|}
\hline & $\begin{array}{c}\text { Saldo de } \\
\text { Mulheres }\end{array}$ & $\begin{array}{c}\% \text { de } \\
\text { mulheres no } \\
\text { saldo total }\end{array}$ & $\begin{array}{c}\text { Salário Médio } \\
\text { das Mullheres } \\
\text { adimitidas }\end{array}$ & $\begin{array}{c}\text { Relação entre } \\
\text { Salário Médio } \\
\text { Mullheres } \\
\text { /Homens }\end{array}$ \\
\hline $\begin{array}{c}\text { Região } \\
\text { Metropolitana de } \\
\text { Campinas } \\
\text { São Paulo }\end{array}$ & -4.935 & $56 \%$ & $\mathrm{R} \$ 1.525,39$ & 0,80 \\
BRASIL & -45.941 & $42 \%$ & $\mathrm{R} \$ 1.714,29$ & 0,90 \\
\hline
\end{tabular}

Fonte: CAGED, 2018

Para o lançamento da plataforma do Observatório PUC-Campinas foi organizado um primeiro Estudo Temático com as informações detalhadas sobre a evolução do mercado de trabalho na RMC no período de 2006 a 2018. Além de mapear as características da atividade econômica local, a partir mercado de trabalho regional, tal estudo representou um ponto de partida para compreender as especificidades do uso de trabalho na RMC, como por exemplo padrões de remuneração e rotatividade. 
Figura 3 - Algumas informações disponibilizadas no Estudo Temático 1
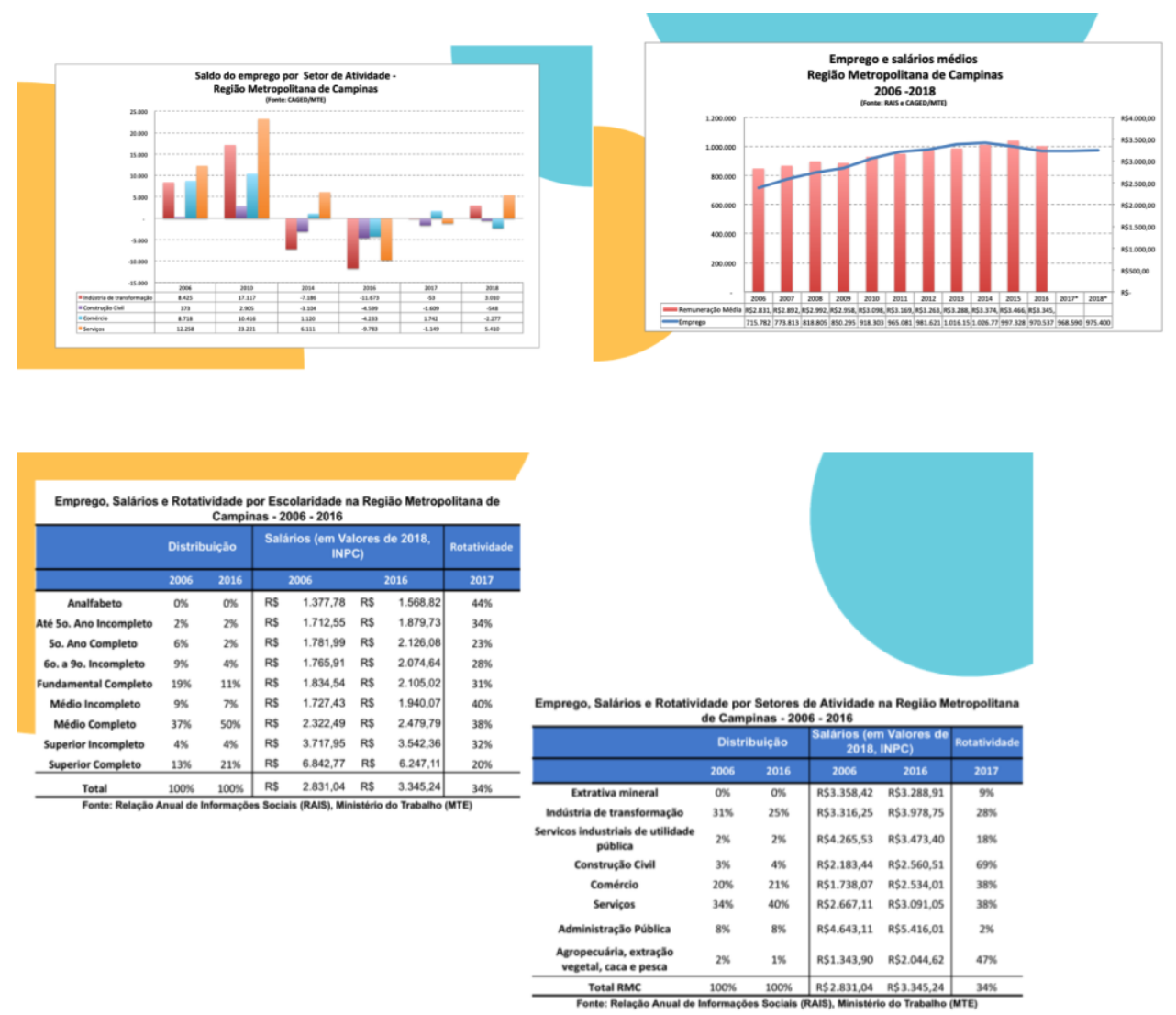

Fonte: Observatório PUC-Campinas

No final de 2018, a partir de uma reunião na AGEMCAMP na Câmara Temática (CT) do Turismo em 29/11/2018. Pode ser elaborado o segundo estudo temático sobre a Economia do Turismo da RMC.

As reflexões iniciais foram paulatinamente sendo construídas pelos os representantes dos 20 municípios da RMC partícipes da Câmara Temática do Turismo.

A Secretaria do Turismo, na Prefeitura Municipal de Campinas disponibilizou um conjunto de informações sobre a atividade de turística no município, foi possível elaborar o Estudo Temático do Turismo que chama atenção para outras atividades de turísticas além do turismo de negócios. Revelando assim, o potencial da RMC em desenvolver roteiros combinados entre os municípios.

Seguem alguns pontos apresentados e discutidos nesta CT, que deram origem ao Estudos Temático 
Figura 4 - Algumas Informações divulgadas pelo Estudo Temático 2

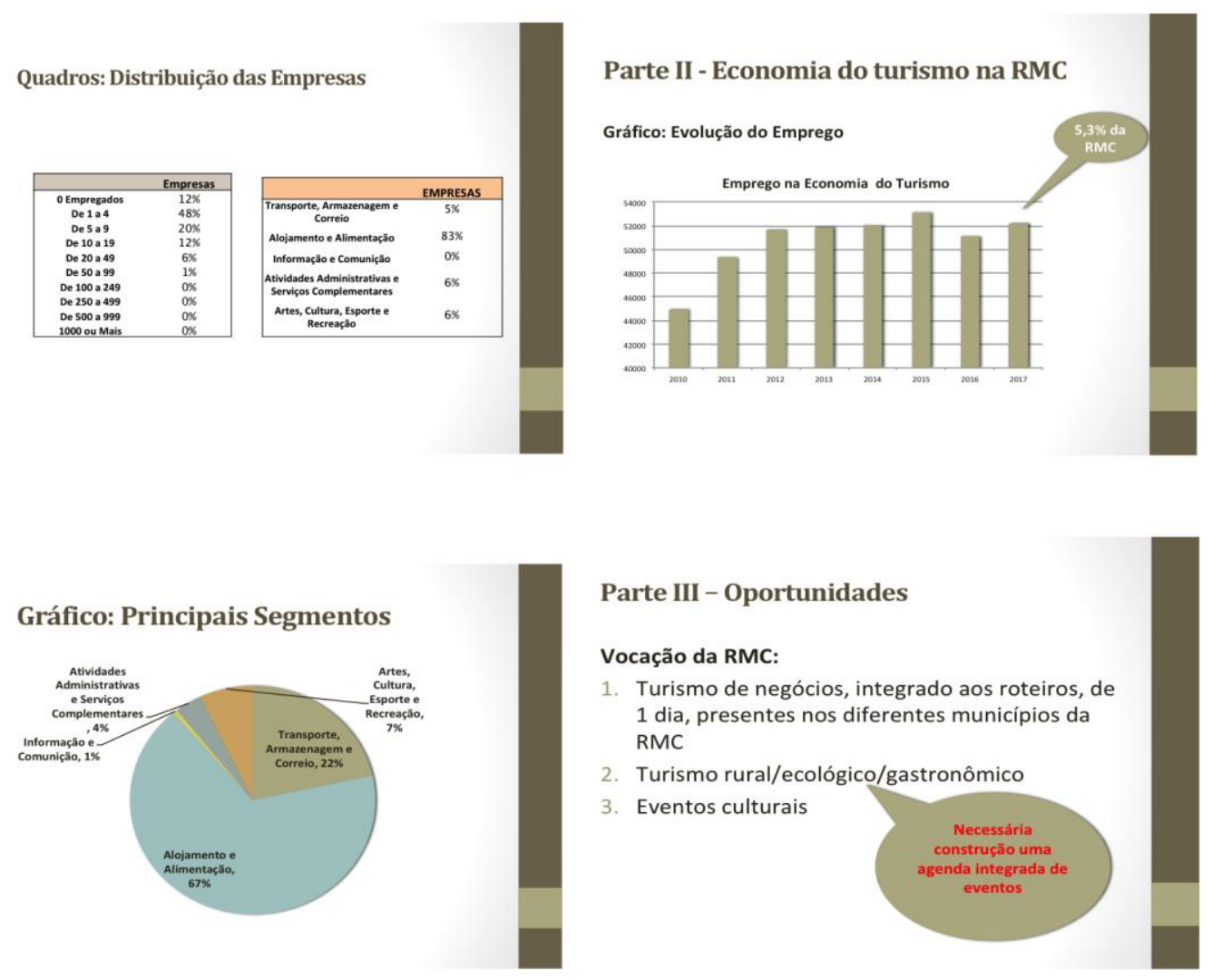

Fonte: Observatório PUC-Campinas

Em março de 2019, foi lançado na plataforma do observatório o terceiro Estudo Temático que aborda a trajetória das mulheres no mercado de trabalho na RMC. Neste estudo são apontados os desafios enfrentados pelas mulheres que ingressam no mercado de trabalho em posição de desvantagem salarial em relação aos homens. Discute-se neste estudo que há um processo de discriminação em que as mulheres em geral são selecionadas para setores econômicos e postos de trabalho de menor produtividade que os homens.

Figura 5: Algumas informações divulgadas no Estudo Temático 3 
Fluxo do emprego na RMC - 2010 a 2018

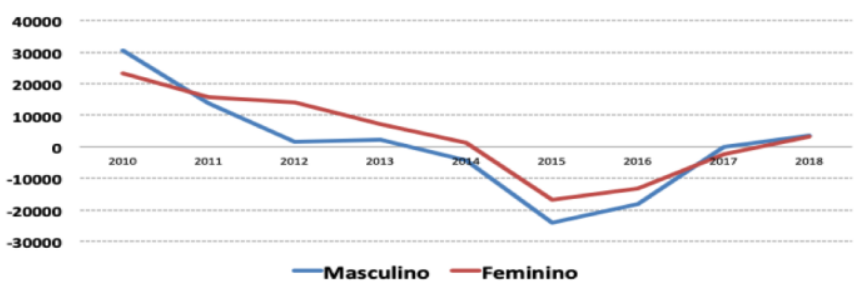

Importante destacar:

no total, entre 2010 e 2018 foram gerados pouco mais de $37 \mathrm{mil}$ empregos, dos quais 32,5 mil foram para mulheres

Mais algumas características do emprego gerado entre 2010 e 2018

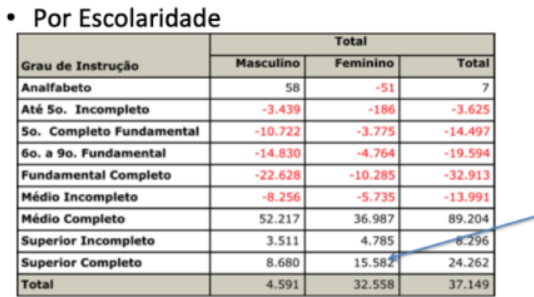

Mais uma estratégia de reduçao de custos:

- Salário das mulheres admitidas com superior completo: $65 \%$ do pago aos homens

\begin{abstract}
Relação entre salário feminino e salário masculino na RMC por grupo de ocupação
\end{abstract}

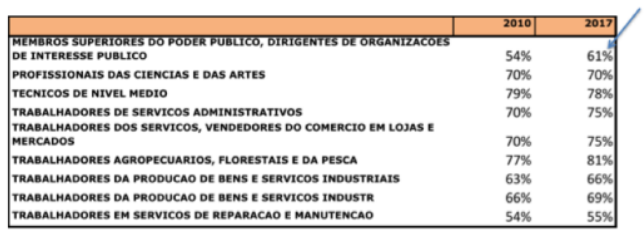

Importante: em todos os grupos ocupacionais o padrão de remunerção é desfavorável para as mulhere

Fonte: Observatório PUC-Campinas

Por fim, cabe destacar a repercussão na mídia e novos parceiros. Inicialmente, a produção dos informativos mensais sobre o do mercado de trabalho regional e dos Estudos Temáticos foi bem recebida pela mídia local. A Figura 6 comprova como veículos de informação passaram a utilizar tais informações como conteúdo de suas matérias. Tal fato pode sinalizar o início da consolidação do Observatório como fonte confiável junto à sociedade civil. Acredita-se que tal reconhecimento permitiu que alguns representantes de prefeituras e membros de instituições de organizações da sociedade civil iniciassem as tratativas para estabelecer parcerias com a PUCCampinas para utilizar as informações do Observatório.

Figura 6: Repercussão na mídia 


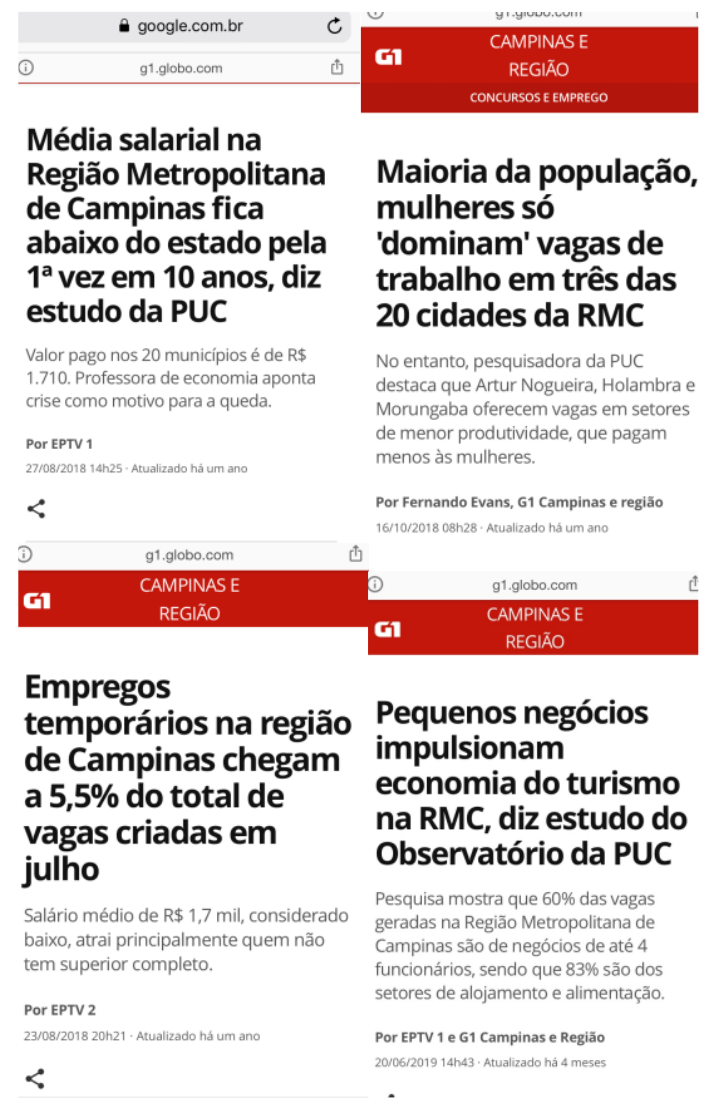

Fonte: G1, Portal de Notícias, www.g1.globo.com, 2019.

\section{CONCLUSÕES}

Diante do exposto, conclui-se, com o apoio institucional da universidade, o projeto de extensão Observatório Econômico da PUC-Campinas alcançou os objetivos inicialmente colocados.

Bases de dados complexas, quando transformadas em gráficos, tabelas e indicadores, permitem que as informações sejam disseminadas de uma maneira mais fácil ao público. Os textos utilizados nos Informativos Mensais e, mesmo nos Estudos Temáticos realizados, objetivam facilitar e ampliar a compreensão de quem não é da área de Economia.

Com base nos informativos já divulgados e nos indicadores e dados neles apresentados, ficou evidente que a Região tem passado por mudanças estruturais importantes no tocante do Emprego e Renda, que afetam diretamente a vida dos que aqui residem. Por conta disto, é necessária existência de uma plataforma que esteja atenta a tais tendências, tornando-as de conhecimento para todos.

Ficou clara também a importância dessa plataforma para aproximação da Universidade com canais de mídia da RMC. A produção de conteúdo sendo bem recebida pela mídia local 
tende a confirmar a importância da construção de um Observatório para o meio em que está inserido, visto que é capaz de apresentar elementos capazes de contribuir para o debate e a reflexão de temas relacionados ao desenvolvimento local.

Acredita-se que daqui pra frente essa plataforma poderá ter um crescimento sólido e sustentável, sendo capaz de gerar sinergias para que os projetos de pesquisa e extensão da Universidade e sejam articulados às demandas da Região Metropolitana de Campinas.

Encerra-se esse artigo com a compreensão de que para a comunidade externa, esses indicadores podem ajudar as Prefeituras dos municípios da RMC na formulação de Políticas Públicas. Além disso, o público em geral, tem acesso a uma informação transparente e de fácil compreensão.

Vale lembrar, a Região Metropolitana de Campinas é uma região de extrema importância econômica no Brasil, já que carrega consigo uma parcela bastante significativa do PIB. Este projeto de extensão ao revelar estas características por meio do "Observatório Econômico da PUC-Campinas" cumpre sua importância.

Para o próximo ano espera-se manter a continuidade de dos informativos mensais e dar continuidade à Elaboração dos Estudos Temáticos. Para atender aos objetivos estabelecidos no Projeto de extensão aprovado, a meta é produzir no mínimo 4 estudos e 12 Informativos Mensais.

Além disso, como a visibilidade do Observatório PUC-Campinas despertou o interesse de diferentes atores sociais em estabelecer projetos conjuntos nos temas de geração de trabalho e renda, acredita-se que a ampliação desta rede de parceiros propiciará a ampliação de acesso às novas informações que permitirão a construção de novos Estados Temáticos.

Um fator importante de preocupação a ser sublinhado diz respeito à extinção do Ministério do Trabalho e Emprego por parte do governo federal e o desmembramento de suas funções por outros ministérios. Por enquanto, os dados estatísticos continuam sendo disponibilizados à comunidade acadêmica para a elaboração das análises, todavia dada as intensidades das mudanças em curso, é importante deixar sinalizado que eventualmente pode haver uma interrupção na divulgação dos dados oficiais do mercado de trabalho brasileiro.

\section{REFERÊNCIAS BIBLIGRÁFICAS:}


ALBORNOZ, L., HERSCHMANN, M. (1). Os observatórios ibero-americanos de informação, comunicação e cultura: balanço de uma breve trajetória. E-Compós, 7. 2006.

BeUtTenmuller, G. (2007) Observatórios Locais de Políticas Públicas no Brasil: seu papel na produção, disseminação e transparência das informações, Dissertação de Mestrado, FGV, 2007.

FELTRE, C. BERNARDES, A., ADAMSON G.S., OLIVEIRA, H. (2016) Observatório de políticas públicas da região metropolitana de Campinas/SP (RMC). Revista Ciência em Extensão, v.12, nr3, 2016.

SERAFIM, L. (2008) Controle social: que caminhos? Observatório dos direitos do cidadão/Participação Cidadã. Instituto Polis, USP, Julho de 2008.

SOARES, L. FERNEDA, E. PRADO, H. Observatórios: um levantamento do estado do conhecimento. Brazilian Journal of Information Studies: Research Trends. 12:3 (2018) p.86-p.110.

VARGAS, F.E.B (2015) Observatório Social do Trabalho: desfiando o conhecimento, as políticas de emprego e o diálogo Social, Revista Expressa Extensão Pelotas, v. 20, n. 2 p. 141-152, 2015.

Sites consultados:

CADED e RAIS: http://pdet.mte.gov.br/acesso-online-as-bases-de-dados

Observatório PUC-Campinas: https://www.puc-campinas.edu.br/observatorio-puccampinas/

G1: https://g1.globo.com/sp/campinas-regiao/

Recebido em: 26 de setembro de 2019.

Aceito em: 18 de março de 2020. 